\title{
Use of a Wild-Type Gene Fusion To Determine the Influence of Environmental Conditions on Expression of the S Fimbrial Adhesin in an Escherichia coli Pathogen
}

\author{
THOMAS SCHMOLL, ${ }^{1}+$ MANFRED OTT, ${ }^{1}$ BAUKE OUDEGA, ${ }^{2}$ AND JÖRG HACKER ${ }^{1 *}$ \\ Institut für Genetik und Mikrobiologie, University of Würzburg, Röntgenring 11, D-8700 Würzburg, Federal Republic of \\ Germany, ${ }^{1}$ and Department of Molecular Microbiology, Free University, NL-1007 Amsterdam, The Netherlands ${ }^{2}$
}

Received 31 January 1990/Accepted 18 June 1990

\begin{abstract}
S fimbrial adhesins (Sfa) enable pathogenic Escherichia coli strains to bind to sialic acid-containing eucaryotic receptor molecules. In order to determine the influence of culture conditions on the expression of the $s f a$ determinant in a wild-type strain, we fused the gene lacZ, coding for the enzyme $\beta$-galactosidase, to the $s f a A$ gene, responsible for the major protein subunit of $S$ fimbriae. By using a plasmid which carries an $R 6 \mathrm{~K}$ origin, the sfaA-lac hybrid construct was site-specifically integrated into the chromosome of the uropathogenic $E$. coli strain 536WT. The expression of lacZ, which was under the control of the sfa wild-type promoters, was now equivalent to the sfa expression of strain 536WT. With the help of this particular wild-type construct, it was demonstrated that the sfa determinant is better expressed on solid media than in liquid broth. The growth rate had a strong influence on Sfa expression under aerobic but not under anaerobic conditions. Production of Sfa was further regulated by catabolite repression, osmolarity, and temperature.
\end{abstract}

Escherichia coli strains are able to cause infections of the bladder and the kidney (urinary tract infections) and cases of newborn meningitis $(26,37)$. Such extraintestinal $E$. coli strains express different kinds of fimbrial adhesins, which enable bacteria to colonize eucaryotic tissues $(11,19)$. Fimbrial adhesins can be distinguished by their receptor specificity. Type I fimbriae bind to mannose-containing receptors and are expressed by both pathogenic and nonpathogenic $E$. coli strains $(10,23)$. P fimbriae, which are predominantly found among uropathogenic $E$. coli strains, are able to recognize $\alpha$-D-Gal-(1-4)- $\beta-D-G a l$ moieties of glycolipids located on different cells $(4,22)$. In contrast, $S$ fimbrial adhesins (Sfa) facilitate binding of bacteria to receptors containing $\alpha$-sialic acid-(2-3)- $\beta$-Gal residues $(16,41)$. $S$ fimbriae are commonly found on $E$. coli $\mathrm{K} 1$ strains causing newborn meningitis and on uropathogenic $\mathrm{O6}$ isolates (18, 26, 38).

The genetic determinant coding for Sfa was cloned from the chromosome of a uropathogenic $\mathrm{O} 6$ strain and genetically characterized $(16,18,35,39,46)$. It was demonstrated that Sfa directly contribute to nephropathogenicity in rats (30). They enable $E$. coli strains to bind to tissue sections of the human urinary tract and of the rat brain $(40,53)$. Convincing evidence exists that Sfa are not produced constitutively; rather, the expression of Sfa varies during the infectious process and after cultivation in vitro (44). Therefore, it is speculated that different environmental conditions may influence the production of $S$ fimbriae in wild-type strains.

In order to determine the influence of such environmental signals accurately, we have constructed an SfaA-Lac translational wild-type fusion protein. This gene fusion, which is under the control of the sfa promoter region on the chromo-

\footnotetext{
* Corresponding author.

† Present address: Dept. of Pathology, University of Cambridge, Cambridge, U.K.
}

some of the wild-type pathogen $E$. coli $536 \mathrm{WT}$, was used here as a tool for measuring the influence of different environmental signals on the expression of Sfa.

\section{MATERIALS AND METHODS}

Bacterial strains used. From the uropathogenic $E$. coli strain 536WT (O6:K15:H31), a sfaA-lac wild-type gene fusion was isolated. Strain 536WT has been characterized elsewhere $(16 \mathrm{a}, 24)$. As a prerequisite for the isolation of an sfa-lac wild-type fusion, we isolated a $\mathrm{Lac}^{-}$mutant from the $\mathrm{Lac}^{+}$strain 536WT. Plasmid pRT733, which carries a TnphoA element $(34,50)$, was introduced into strain 536WT. Since pRT733 is unable to replicate in strain 536WT, kanamycin-resistant mutants must carry TnphoA inserted into the chromosome. The $\mathrm{Lac}^{-}$mutant 536-9B4 was detected after cultivation on MacConkey agar plates as well as on agar plates containing X-Gal (5-bromo-4-chloro-3-indolyl- $\beta$ $D$-galactopyranoside) and IPTG (isopropyl- $\beta$-D-thiogalactopyranoside). Chromosomal DNA was isolated from strain 536-9B4 and hybridized with lacZ- as well as with Tn5specific radioactively labeled DNA probes. The hybridizations showed that the TnphoA element was inserted directly into the lacZ locus. DNA isolated from strain 536-9B4 but not from 536WT specifically reacted after hybridization with a DNA probe which contained $\mathrm{Tn} 5$ sequences (data not shown). Strain 536-17B1 was used as an $\mathrm{Sfa}^{-}$control (Ott and Hacker, unpublished results). The $E$. coli $\mathrm{K}-12$ strain SM10 ( $\lambda$ pir) was used for conjugation experiments (50).

Plasmids used. Plasmids pJM703-1 (Ap') and pRT733 (Apr $\left.\mathrm{Km}^{\mathrm{r}} \mathrm{Tn} p h o A\right)$, which carry the R6K origin $(34,50)$, were mobilized into strain 536, which is a $\mathrm{Pir}^{-}$strain. The recombinant plasmids are able to replicate only in the presence of the Pir protein; therefore, they are not able to survive in strain 536WT. Plasmid pDS410 was used for the isolation of Tn5-specific sequences (7); pANN801-13 is an $\mathrm{Sfa}^{+}$plasmid (18); pANN1403-381 carries a site-specific sfaA-lac fusion (5, 16, 17; T. Schmoll, J. Morschhäuser, M. 


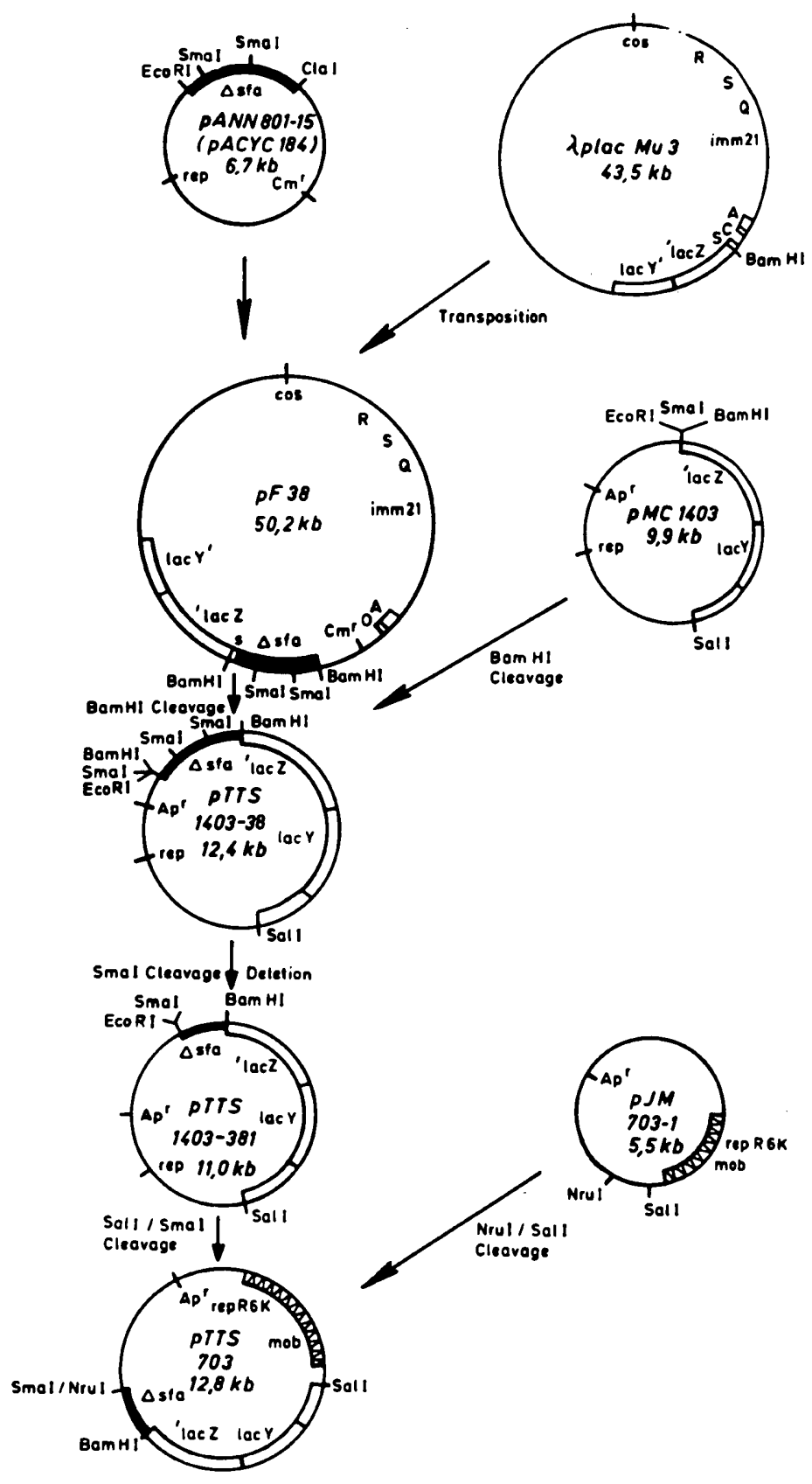

FIG. 1. Construction of plasmid pTTS703, which was used for the site-specific insertion. A Aplac Mu3 fusion with plasmid pANN801-15, containing the proximal part of the $s f a$ gene cluster, was constructed. The $s f a$-specific sequences of the resulting construct pF 38 were ligated into the BamHI site of pMC1403, leading to plasmid pTTS1403-38. A further deletion of the sfa-specific SmaI fragment, carrying the sfa promoters, generated plasmid pTTS1403-381. The Sall-Smal fragment of this construct was then cloned into the pJM703-1 suicide vector, resulting in plasmid pTTS703, which could then be mobilized into strain 536-9B4 (see Fig. 2).

Ott, B. Ludwig, J. Van Die, and J. Hacker, Microb. Pathog., in press). The recombinant plasmid pTTS703, which consists of the vector pJM703-1 and promotorless sfa sequences fused to $l a c Z$, was used for a site-specific integration of $\Delta s f a A$-lacZ sequences into the chromosomally encoded $s f a$ determinant of strain 536-9B4. The construction of plasmid
pTTS703 is indicated in Fig. 1. As a prerequisite, plasmid pF38 was cleaved with BamHI. Plasmid pF38 consists of the phage $\lambda$ plac Mu-3, and the recombinant DNA pANN801-15 carries the proximal part of the sfa determinant $(17,18)$. A BamHI fragment ( 2.7 kilobases [kb] in size) of pF38 containing the $5^{\prime}$ end of the $s f a$ determinant, including its promoter 
region, and the structural gene $s f a A$ was ligated into the vector pMC1403 to construct plasmid pTTS1403-38 (5). The deletion of an SmaI fragment containing the sfa promoter sequences from plasmid pTTS1403-38 resulted in plasmid pTTS1403-381. The latter was used to insert the promoterless $\Delta s f a A$-lacZ-containing $S m a I-S a l I$ fragment into the suicide vector pJM703-1.

Media, chemicals, and enzymes. Bacteria were grown in LB (Luria-Bertani) broth as described before (18). For fermentor experiments, LB broth was supplemented with 5 $\mathrm{mM}$ potassium phosphate buffer.

The recombinant clones were cultivated under selective antibiotic pressure with ampicillin $(50 \mu \mathrm{g} / \mathrm{ml})$, chloramphenicol $(20 \mu \mathrm{g} / \mathrm{ml})$, and tetracycline $(20 \mu \mathrm{g} / \mathrm{ml})$. Radiochemicals were purchased from New England Nuclear Corp., and antibiotics were a gift from Bayer, Leverkusen, FRG. Restriction enzymes and T4 ligase were purchased from New England BioLabs, Beventon, Mass.

For the detection of $\mathrm{Lac}^{+}$colonies, MacConkey agar plates or LB-X-Gal-IPTG medium (containing $0.01 \% \mathrm{X}$-Gal and $0.05 \mathrm{mM}$ IPTG) was used. All other chemicals were obtained from Merck, Darmstadt, FRG.

Growth conditions and fermentor modes. To study the influence of the specific growth rate $(\mu)$ of bacteria on Sfa production, strain 536-9B4/12 was grown in 500-ml continuous chemostat cultures at $37^{\circ} \mathrm{C}$ in LB medium and at a controlled $\mathrm{pH}$ of 7.0 as described before (52). The $\mathrm{O}_{2}$ level was kept constant, and the experiments were done under selective pressure. The doubling times were similar after aerobic and anaerobic cultivation ( 35 to $40 \mathrm{~min}$ ), indicating nearly identical maximal growth rates $\left(\mu_{\max }\right)$ of about 1.0 $\mathrm{h}^{-1}$ after growth under both conditions. The expression of Sfa was measured after 40 to $47 \mathrm{~h}$ of incubation at steadystate conditions with specific growth rates $(\mu)$ of $0.1 \mathrm{~h}^{-1}$ and after 10 to $15 \mathrm{~h}$, when the cultures were at a $\mu$ of 0.6 to 0.7 $\mathrm{h}^{-1}$. The influence of catabolite repression on Sfa production was measured after growing strain $536-9 B 4 / 12$ on solid LB medium with and without $0.4 \%$ glucose and/or $1 \mathrm{mM}$ cyclic AMP. The influence of osmolarity and temperature on Sfa expression was also measured after cultivation of bacteria on LB agar plates.

Recombinant DNA techniques. Isolation of plasmid DNA was carried out as described before $(3,15)$. Cleavage of DNA was done under conditions described by the manufacturer. Gel electrophoresis was carried out in 0.7 to $1.0 \%$ agarose. Isolation and purification of DNA fragments from agarose gels were performed by electroelution (29). E. coli strains were transformed by the $\mathrm{CaCl}_{2}$ method (27). Ligations were carried out under standard conditions (29)

TnphoA mutagenesis. Conjugative crosses between the donor strain SM10(pRT733) ( $\lambda$ pir) and the recipient strain 536WT were carried out as described before (34). The mating samples were streaked onto agar medium containing streptomycin $(100 \mu \mathrm{g} / \mathrm{ml})$ and kanamycin $(50 \mu \mathrm{g} / \mathrm{ml})$. 536WT variants which exhibited resistance to streptomycin and kanamycin but not to ampicillin $(100 \mu \mathrm{g} / \mathrm{ml})$ should carry a TnphoA element integrated into the chromosome.

Immunocolony dots. Immunocolony dots were carried out by the method of Van Die et al. (51). Anti-S-fimbriae antibodies were prepared from rabbits inoculated with purified $S$ fimbrial protein eluted from a sodium dodecyl sulfate (SDS)-polyacrylamide electrophoresis gel (35).

Generation of DNA probes. The $s f a$-specific DNA probe was an 8.5-kb EcoRV fragment derived from the plasmid pANN801-13 (18). Plasmid pDS410 contains the 3.4-kb HindIII fragment of $\mathrm{Tn} 5$ in pBR322, which was used as a probe (7). A lac-specific probe was isolated from the vector pMC1403 as a 6.2-kb EcoRI-SalI fragment (5). Only probes which were eluted from agarose gels were used in Southern hybridizations.

Nick translation, Southern hybridization, and autoradiography. The DNA probes were labeled by nick translation with a mixture of all four $\left[\alpha^{-32}\right] \mathrm{P}$-labeled deoxynucleoside triphosphates as described previously (42). Southern transfer, washing, and autoradiography of the filters were carried out as described previously $(29,47)$. The filters were hybridized in $50 \%$ formamide at $43^{\circ} \mathrm{C}$ for 3 days. Stringent conditions were used for the washing procedure: $30 \mathrm{~min}$ at room temperature in $2 \times S S C(1 \times S S C$ is $0.15 \mathrm{M} \mathrm{NaCl}$ plus 0.015 $M$ sodium citrate [pH 7.0]) containing $0.1 \%$ SDS and then four times for $30 \mathrm{~min}$ at $56^{\circ} \mathrm{C}$ in $0.1 \times \mathrm{SSC}-0.1 \%$ SDS.

$\beta$-Galactosidase test. $\beta$-Galactosidase units were determined by the method of Miller (32). Only bacterial populations with equal amounts of cells $\left(\mathrm{OD}_{600}, 0.8\right.$ to 1.0) were compared.

Statistics. Mean values \pm standard deviation were calculated by the method of Cavalli-Sforza (6).

\section{RESULTS}

Construction of the wild-type sfaA-lac fusion 536-9B4/12. The construction of the translational fusion strain 536-9B4/12 is shown in Fig. 2. First, the recombinant plasmid pTTS703, which was unable to replicate in strain 536-9B4, was transferred into the $\mathrm{Lac}^{-}$mutant. In order to select variants with pTTS703 inserted into the chromosomally encoded sfa determinant, ampicillin-resistant transconjugants were tested in an immunocolony dot assay with a monospecific polyclonal antiserum raised against the $S$ fimbrial subunit protein (Table 1). Two of 12 ampicillin-resistant 536-9B4 variants tested were negative in the immunocolony dot assay. This result indicates that pTTS703 had integrated into the $s f a$ gene cluster.

To determine whether pTTS703 was integrated into the sfaA gene of strain 536-9B4, DNA from the $\mathrm{Sfa}^{-}$variant 536-9B4/12 together with DNA from strains 536WT and 536-9B4 was probed with a radioactively labeled $s f a$-specific DNA fragment. As demonstrated in Fig. 3, the strains 536WT and 536-9B4 $\left(\mathrm{Lac}^{-}\right)$hybridized with two EcoRI fragments of the chromosomal DNAs. The smaller EcoRI fragment $\left(4.8 \mathrm{~kb}\right.$ in size) represents the $5^{\prime}$ end of the $s f a$ determinant and includes the structural gene $s f a A$, coding for the major fimbrial subunit $(38,46)$. This fragment was absent in the $\mathrm{Sfa}^{-}$strain 536-9B4/12. However, the appearance of two EcoRI fragments of 7.0 and $14.4 \mathrm{~kb}$ indicates a site-specific integration of pTTS703 into the $s f a A$ gene of strain 536-9B4/12.

Influence of solid and liquid media on the expression of $s f a$. E. coli 536WT and 536-9B4/12, which carries the sfaA-lac fusion on the chromosome, were grown on solid medium and in a noncontinuous liquid culture. As shown in Fig. 4, the lacZ gene of 536-9B4/12 (which is under the control of the $s f a$ promoter) was expressed four times better after cultivation on solid medium than after growth in liquid broth (449 versus $125 \mathrm{U}$ of $\beta$-galactosidase activity). The expression of the lac operon of 536WT induced by IPTG $(0.05 \mathrm{mM})$ was not influenced by the alteration of these growth conditions.

Influence of the specific growth rate under aerobic and anaerobic conditions on the expression of $s f a$. Strain 5369B4/12 was grown under aerobic and anaerobic conditions in continuous cultures. $\beta$-Galactosidase activity was measured in cells cultured under steady-state conditions. As demon- 


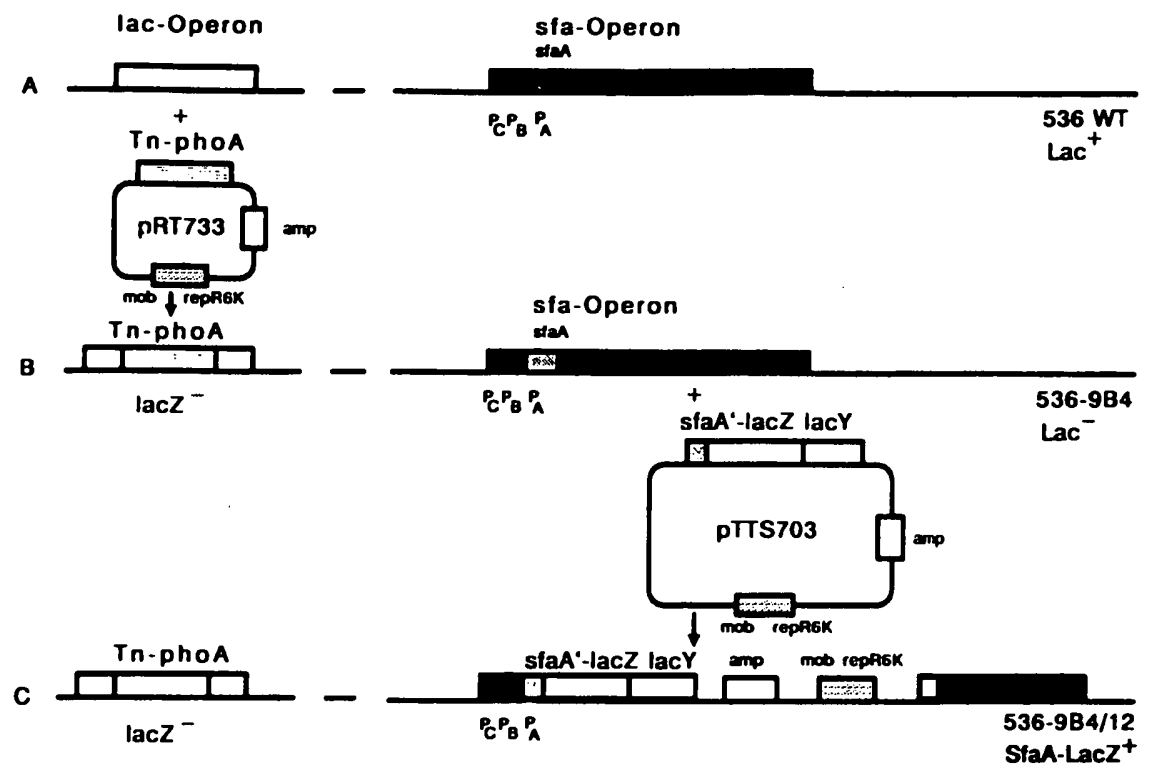

FIG. 2. Generation of the $\mathrm{Lac}^{-}$derivative of the wild-type strain 536-9B4 by insertion of a TnphoA element into the lac gene cluster of strain 536WT (left part) and construction of the site-specific wild-type fusion 536-9B4/12 by integration of plasmid pTTS703 carrying the lacZ gene fused to $s f a A$ into the chromosome of strain 536-9B4 (right part). The $s f a$-specific sequences are shown as black bars, with exception of the $s f a A$ region, which is shown as a stippled box. The promotors $\mathrm{P}_{\mathrm{A}}, \mathrm{P}_{\mathrm{B}}$, and $\mathrm{P}_{\mathrm{C}}$ are indicated below. Designations of strains are given, with the respective Lac phenotypes on the right side. Plasmids used for genetic manipulation are shown between the indicated genome structures of strains.

strated in Fig. 5, in one series of experiments, the specific growth rate $(\mu)$ was set at 0.09 to $0.1 \mathrm{~h}^{-1}$. After growth under aerobic conditions, only $15 \mathrm{U}$ were measured. In contrast, under anaerobic conditions, $160 \mathrm{U}$ were detected. After strain 536-9B4/12 was grown at a specific growth rate of 0.6 to $0.7 \mathrm{~h}^{-1}$, the $s f a$ determinant was expressed under aerobic as well as under anaerobic conditions (160 versus $210 \mathrm{U}$ ). These data indicate that the specific growth rate has a strong influence on Sfa expression under aerobic conditions. Under anaerobic conditions, the specific growth rate had only a small effect on Sfa production.

sfa determinant is regulated by catabolite repression. In order to examine whether the production of Sfa is regulated by catabolite repression, $\beta$-galactosidase production by strain 536-9B4/12 was measured after cultivation in the presence or absence of $0.4 \%$ glucose. As demonstrated in Fig. 6, the presence of glucose had a negative effect on the expression of the wild-type Sfa gene cluster. While $565 \mathrm{U}$ of $\beta$-galactosidase were measured after incubation of 536-

TABLE 1. Production of Sfa and $\beta$-galactosidase by $E$. coli $536 \mathrm{WT}$ and mutants

\begin{tabular}{lcc}
\hline \multirow{2}{*}{ Strain } & \multicolumn{2}{c}{ Phenotype } \\
\cline { 2 - 3 } & $\mathrm{Sfa}^{+}$ & $\mathrm{Lac}^{+}$ \\
\hline $536 \mathrm{WT}$ & + & + \\
$536-9 \mathrm{~B} 4$ & + & - \\
$536-9 \mathrm{~B} 4 / 12$ & - & $+^{b}$ \\
$536-17 \mathrm{~B} / 1$ (control) & - & + \\
\hline
\end{tabular}

${ }^{a} \mathrm{Sfa}^{+}$was tested in an immunocolony dot assay with anti-SfaA antiserum. $\mathrm{Lac}^{+}$was tested after cultivation of strains on MacConkey and X-Gal-IPTG plates.

${ }^{b} \beta$-Galactosidase production depended on the regulatory signals of the sfa gene cluster.
9B4/12 on a glucose-free medium (Fig. 6A), $45 \mathrm{U}$ were produced after growth on a medium containing $0.4 \%$ glucose (Fig. 6B). Production of $\beta$-galactosidase was restored after 1 $\mathrm{mM}$ cyclic AMP was added to the medium (Fig. 6C), indicating that the dramatic effect of glucose on Sfa expression depends on catabolite repression. Glucose and cyclic AMP also had a strong effect on the expression of the lac determinant of the wild-type strain 536WT, which was induced by IPTG $(0.05 \mathrm{mM})$.

Influence of osmolarity on the expression of $s f a$. To study the influence of osmolarity on Sfa expression, strains 5369B4/12 and 536WT were grown on LB plates containing different amounts of sodium chloride. As shown in Fig. 7, the $s f a$ gene cluster was optimally expressed after cultivation on plates with $43 \mathrm{mM} \mathrm{NaCl}$. The production of $\beta$-galactosidase by strain 536-9B $4 / 12$ decreased with increasing amounts

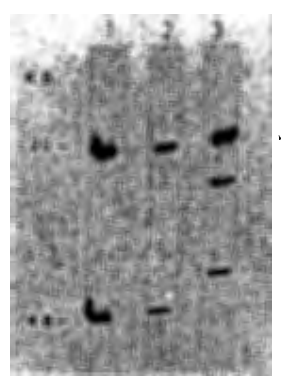

FIG. 3. Southern blot hybridization patterns of EcoRI-cleaved genomic DNAs of $E$. coli strains 536WT ( $\mathrm{Sfa}^{+} \mathrm{Lac}^{+}$, lane 1), 536-9B4 ( $\mathrm{Sfa}^{+} \mathrm{Lac}^{-}$, lane 2), and 536-9B4/12 (sfaA-lac $\mathrm{Sfa}^{-} \mathrm{Lac}^{+}$, lane 3). The DNAs were hybridized to nick-translated DNA probe specific for sfa $(5,7,18)$ (see text). The respective alterations in the fragment pattern are marked $(X)$. 


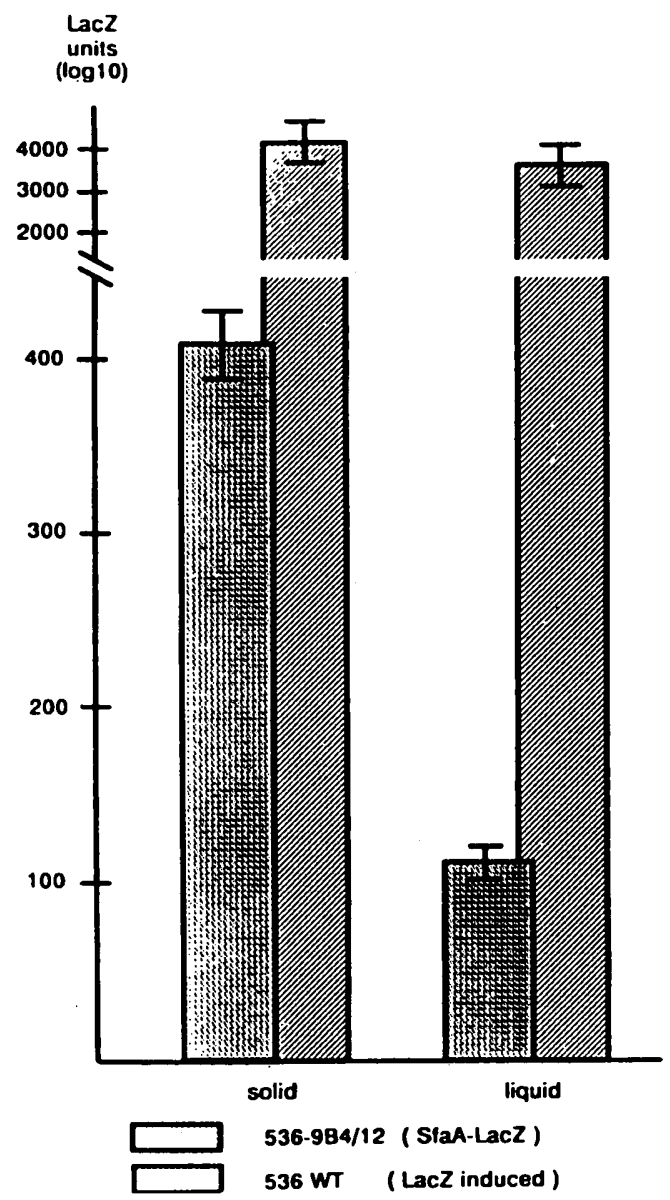

FIG. 4. $\beta$-Galactosidase ( $\mathrm{LacZ}$ ) production, given as $\mathrm{LacZ}$ units on a logarithmic scale for wild-type strain 536WT and the fusion strain 536-9B4/12 grown on solid or liquid medium under aerobic conditions. LacZ production by 536WT was induced by addition of $0.05 \mathrm{mM}$ IPTG. Mean values \pm standard deviation are given.

of $\mathrm{NaCl}$. The expression of the lac wild-type determinant induced by IPTG $(0.05 \mathrm{mM})$ was only slightly affected by the differences in the $\mathrm{NaCl}$ content of the medium.

Influence of temperature on the expression of $s f a$. Strains 536-9B4/12 and 536WT were grown at different temperatures. As shown in Fig. 8, optimal expression of $\beta$-galactosidase, representing Sfa production, was obtained at $37^{\circ} \mathrm{C}(471$ $U$ ). At $20^{\circ} \mathrm{C}$, no production of $\beta$-galactosidase was detected. After a temperature shift from 37 to $43^{\circ} \mathrm{C}$, the values dropped significantly to $23 \mathrm{U}$. As a control, the $\beta$-galactosidase production of 536WT induced by IPTG $(0.05 \mathrm{mM})$ was estimated; it was not significantly influenced by temperature.

\section{DISCUSSION}

In this report we describe the construction and characterization of a pathogenic $E$. coli wild-type strain carrying a gene fusion of the fimbrial determinant $s f a$ and the lacZ indicator gene. The $s f a$ gene cluster codes for Sfa, which enable extraintestinal $E$. coli strains to bind to sialic acidcontaining receptor structures $(26,41)$. The wild-type construction 536-9B4/12 is identical to the uropathogenic strain 536WT with the exception of a TnphoA insertion in the

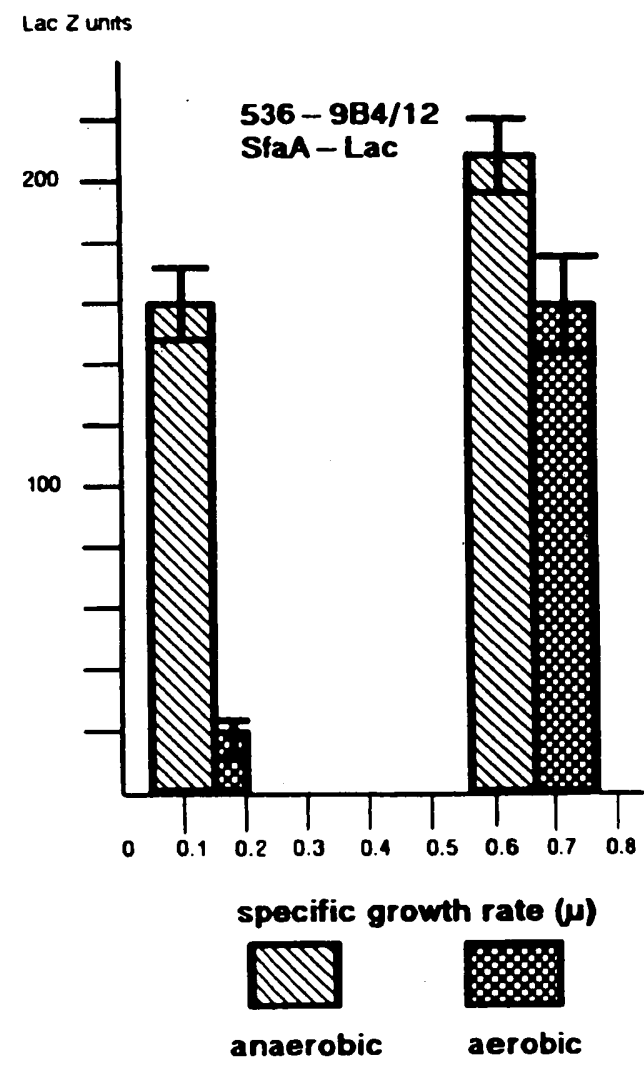

FIG. 5. $\beta-$ Galactosidase (LacZ) production, given as LacZ units, of the fusion strain 536-9B4/12 grown in a continuous culture under aerobic and anaerobic conditions at different specific growth rates $(\mu)$. Mean values \pm standard deviation are given.

original lacZ gene and the fusion of a second lacZ locus to the sfa gene cluster.

Compared with gene fusions constructed in multicopy systems $(1,14)$ or in the $E$. coli $\mathrm{K}-12$ chromosome $(4)$, or with immunological approaches with pathogenic strains $(9$, 43), the wild-type gene fusion shows several advantages. (i) An undesirable multicopy effect, which could counteract the regulatory events under question in plasmid systems, is excluded. (ii) $E$. coli wild-type strains, such as strain 536WT, but not $E$. coli $\mathrm{K}-12$ isolates may carry more than one fimbrial adhesin determinant, which may have the capacity to trans-complement each other $(13,16 \mathrm{a}, 19)$. Such complementation processes may influence the expression of adhesin gene clusters. (iii) Pathogenic $E$. coli wild-type isolates and $E$. coli K-12 laboratory strains differ in their genome structure $(16 \mathrm{a}, 19)$. It has been shown that pathogenic strains carry large DNA regions (pathogenicity DNA islands) harboring virulence determinants. These DNA regions, which are absent in $E$. coli $\mathrm{K} \cdot 12$, may carry additional transregulatory genes influencing the expression of virulence gene clusters (24). (iv) The cell surfaces of wild-type strains are different from those of K-12 laboratory strains in several aspects, including the presence of capsules and O-repeating units, which are present in pathogenic but absent in $\mathrm{K}-12$ strains. These constituents of the cell surface influence the uptake of ions and other substances which are known to have an effect on gene expression (48). (v) Environmental stimuli may influence the expression of genes as well as the 


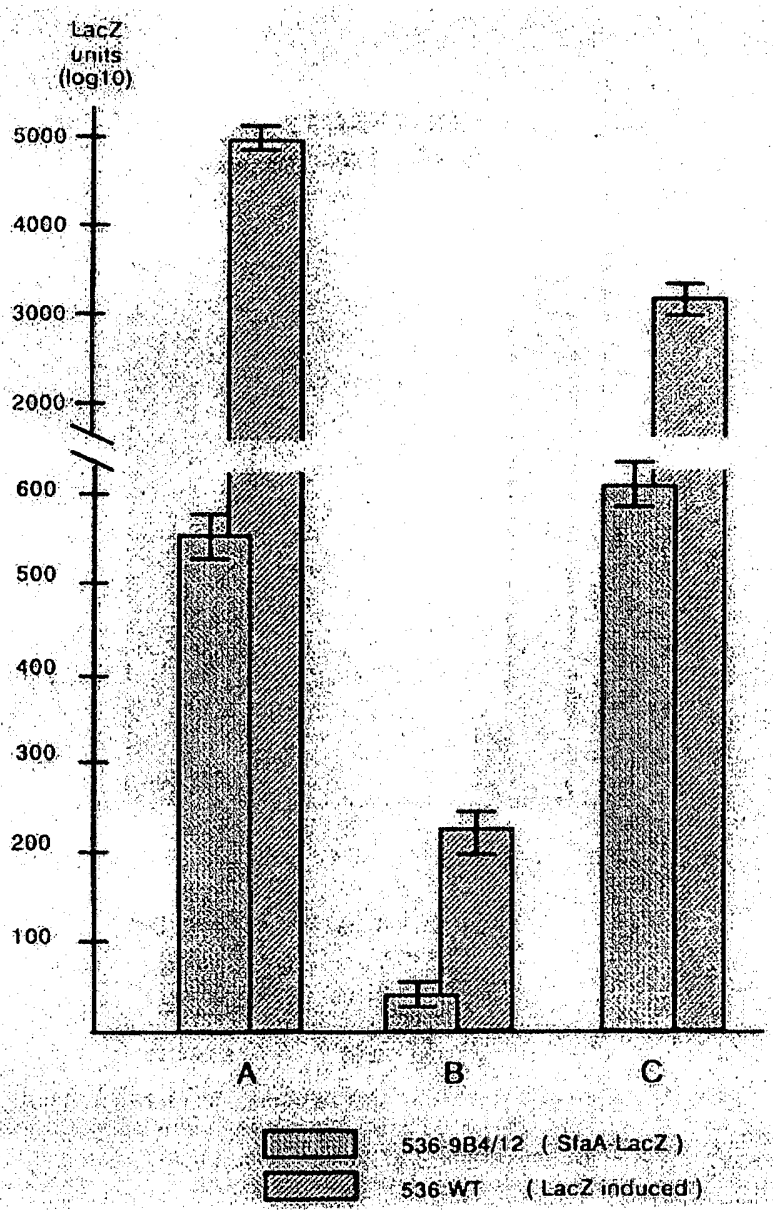

FIG. 6. $\beta-$ Galactosidase (LacZ) production, given as LacZ units on a logarithmic scale, by the wild-type strain $536 \mathrm{WT}$ and the fusion strain 536-9B4/12 grown on solid medium without glucose (A), with $0.4 \%$ glucose (B), and with $0.4 \%$ glucose plus $1 \mathrm{mM}$ cyclic AMP (C) under aerobic conditions. LacZ production by 536WT was induced by addition of $0.05 \mathrm{mM}$ IPTG (see text). Mean values \pm standard deviation are given.

transport and assembly processes of subunit proteins into fimbrial structures $(20,43)$. With the help of the translational fusion used here, however, the direct effects of physiological signals on the expression of the Sfa in the wild-type isolate can be measured.

In general, the expression of bacterial pathogenicity determinants is affected by multiple physiological signals $(8$, 11). The production of Sfa directly depends on the specific growth rate $(\mu)$ of strain 536WT. Significant differences were observed between aerobic and anaerobic growth conditions. While at high $\mu$ the expression under both conditions was high, at low $\mu$ the sfa gene cluster was expressed only under anaerobic conditions. The influence of oxygen on $s f a$ expression, however, seems to be restricted to steady-state conditions and was not observed after growing the wild-type strain in batch cultures (Hacker, unpublished results). It is interesting that the expression of Sfa is further induced after cultivation of strains on solid medium. Such an induction of genes by surface cultivation was recently observed for the lateral flagella gene cluster of Vibrio parahaemolyticus (2). It can be speculated that in both cases an attachment of

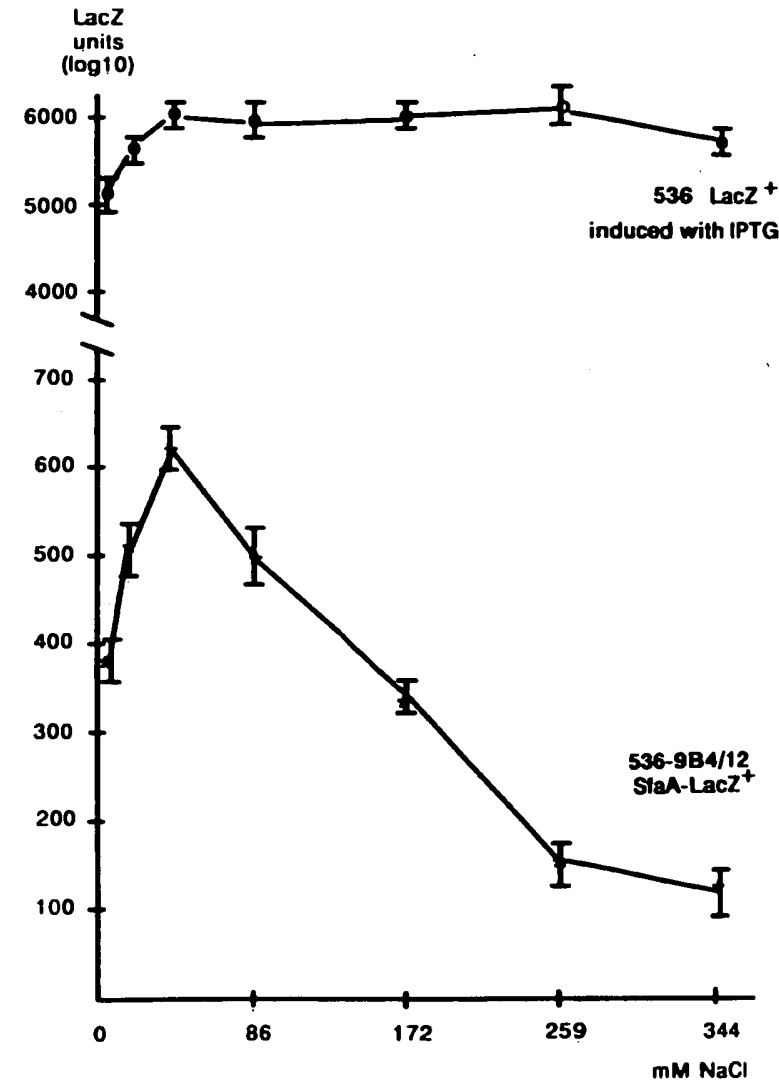

FIG. 7. Influence of the $\mathrm{NaCl}$ content of the medium on $\beta$-galactosidase (LacZ) production, given as $\mathrm{LacZ}$ units on a logarithmic scale, by the wild-type strain 536WT and the fusion strain 5369B4/12 grown on solid medium under aerobic conditions. LacZ production by 536WT was induced by addition of $0.05 \mathrm{mM}$ IPTG (see text). Mean values \pm standard deviation are given.

organisms, which is a prerequisite for the formation of microcolonies, triggers full expression of these gene clusters, which are necessary for settlement of the corresponding organisms on surfaces.

Osmolarity represents another physiological parameter influencing the expression of $S$ fimbriae in a wild-type organism. It has been demonstrated that the salt content of the medium also affects the expression of virulence factors of Vibrio cholerae, such as cholera toxin, adhesin and colonization factors, and outer membrane proteins (34). The salt concentration may monitor the adaptation of the bacteria either to the hostile environment or to living conditions outside the host organisms. Another physiological trigger by which microorganisms discriminate between different natural environments is temperature $(21,31)$. It has been shown that the expression of the Sfa is strictly adapted to the temperature of the human body. Such a stringent temperature adaption to $37^{\circ} \mathrm{C}$ was also shown for other adhesins of pathogenic $E$. coli, like P fimbriae (14) and adherence factors produced by intestinal $E$. coli strains $(8,54)$. On the other hand, a new type of a fibronectin-binding adhesin termed curly is expressed but not efficiently assembled at $37^{\circ} \mathrm{C}$, but is produced at $26^{\circ} \mathrm{C}(36)$. It is speculated that curly adhesins, in contrast to the $S$ fimbriae, may be adapted to a nonhostile environment for $E$. coli strains. 


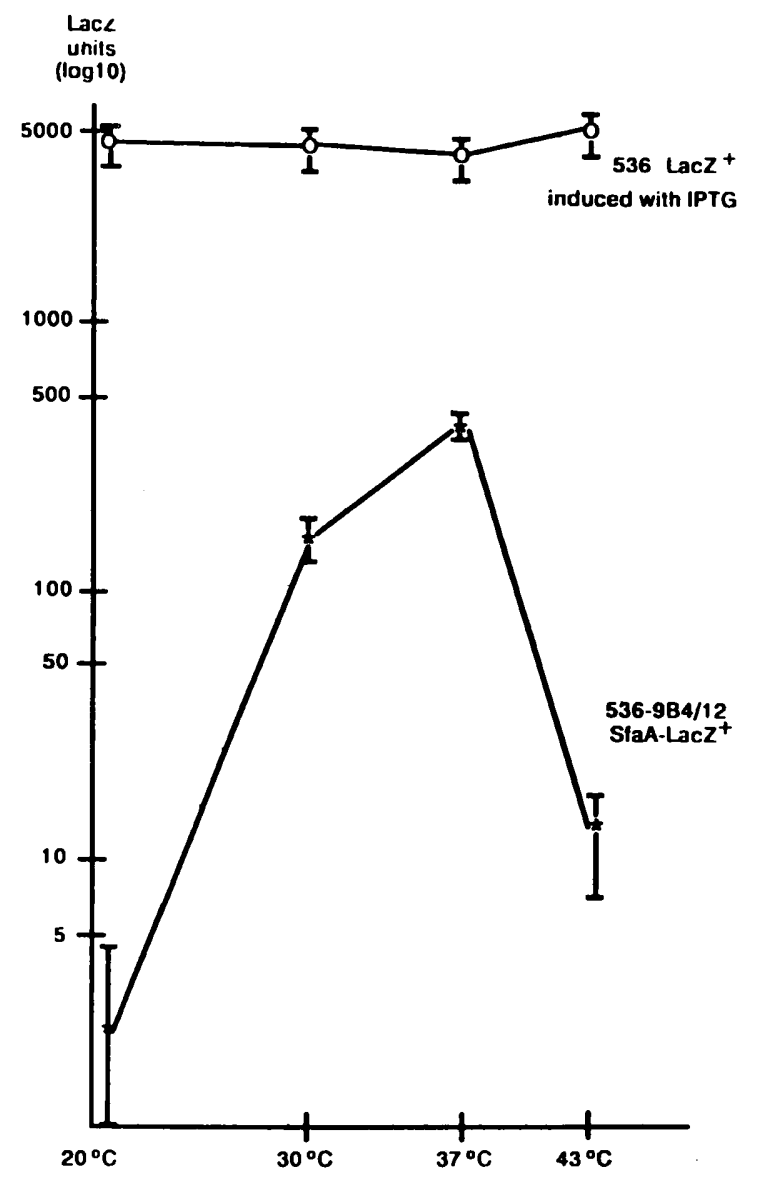

FIG. 8. Influence of growth temperature on $\beta$-galactosidase (LacZ) production, given as LacZ units on a logarithmic scale, by the wild-type strain 536WT and the fusion strain 536-9B4/12 grown on solid medium under aerobic conditions. LacZ production by 536WT was induced by addition of $0.05 \mathrm{mM}$ IPTG (see text). Mean values \pm standard deviation are given.

It was further demonstrated that the presence of glucose negatively influenced the expression of the $s f a$ gene cluster. This repression could be reversed by the addition of cyclic AMP to the culture. Therefore, the expression of $s f a$ shows the characteristic features of catabolite repression (28). It is interesting that a fairly good binding site for the catabolite repression protein exists within the sfa promoter region of strain 536WT (Schmoll et al., unpublished data). Since $E$. coli $\mathrm{P}$ fimbrial gene clusters are also controlled by catabolite repression (12), this mode of regulation might be a basis of linking the expression of a set of virulence-associated genes in a coordinate way. Such trans-regulatory networks are found in different bacterial pathogens. For example, several virulence genes of Vibrio cholerae are coordinately regulated by the factor ToxR, a transmembrane protein which is able to bind to particular DNA regions upstream of virulence-associated genes $(33,50)$.

While ToxR-specific regulation depends on one regulatory element, the virulence genes of Bordetella pertussis, the causative agent of whooping cough, are regulated by a two-component system. One regulatory protein, located in the periplasmic space, receives stimuli from the environ- ment, and following interaction with this component, a second factor acts directly as a DNA-binding protein on the promoter sequences of virulence genes $(25,33)$.

Other two-component systems have been described for the regulation of invasiveness of Salmonella typhimurium, the induction of plasmid transfer from Agrobacterium tumefaciens into plants, and the osmoregulation of $E$. coli outer membrane proteins $(33,49)$. In general, the trans-regulation of pathogenicity gene clusters, which brings unlinked gene clusters under the control of regulatory elements, represents an effective mechanism to adapt bacterial pathogens to certain environments and to distribute cellular energy in an optimal manner.

\section{ACKNOWLEDGMENTS}

We thank J. Mekalanos (Boston, Mass.) for supplying us with plasmids pJM703-1 and pRT733, M. van der Woude (Amsterdam), H. van Verseveld (Amsterdam), and T. Jarchau (Würzburg) for helpful discussions, U. Wallner (Würzburg) for excellent technical assistance, $M$. Wuenscher (Würzburg) for critically reading the manuscript, and H. Kurz (Würzburg) for editorial assistance.

The work was supported by the Deutsche Forschungsgemeinschaft (Ha 1434/1-6).

\section{LITERATURE CITED}

1. Baga, M., M. Göransson, S. Normark, and B. E. Uhlin. 1985 Transcriptional activation of a Pap pilus virulence operon from uropathogenic Escherichia coli. EMBO J. 4:3887-3893.

2. Belas, R., M. Simon, and M. Silverman. 1986. Regulation of lateral flagella gene transcription in Vibrio parahaemolyticus. $\mathrm{J}$. Bacteriol. 167:210-218.

3. Birnboim, H. C., and J. Doly. 1979. A rapid alkaline extraction procedure for screening recombinant plasmid DNA. Nucleic Acids Res. 7:1513-1522.

4. Blyn, L. B., B. A. Braaten, C. A. White-Ziegler, D. H. Rolfson, and D. A. Low. 1989. Phase variation of pyelonephritis-associated pili in Escherichia coli: evidence for transcriptional regulation. EMBO J. 8:613-620.

5. Casadaban, M. J., S. N. Chou, and S. N. Cohen. 1980. In vitro gene fusions that join an enzymatically active $\beta$-galactosidase segment to amino-terminal fragments of exogenous proteins: Escherichia coli plasmid vectors for the detection and cloning of translational initiation signals. J. Bacteriol. 143:971-980.

6. Cavalli-Sforza, L. 1969. Biometrie. Grundzüge biologischmedizinischer Statistik. Fischer-Verlag, Jena, FRG.

7. De Bruijn, F. J., and J. R. Lipski. 1984. The use of transposon Tn5 mutagenesis in the rapid generation of correlated physical and genetic maps of DNA segments cloned into multicopy plasmids-a review. Gene 27:131-149.

8. de Graaf, F. K. 1988 . Fimbrial structures of enterotoxigenic $E$. coli. Antonie van Leeuwenhoek J. Microbiol. Serol. 54: 395-404.

9. de Graaf, F. K., F. B. Wientjes, and P. Klassen-Boor. 1980. Production of K99 antigen by enterotoxigenic Escherichia coli strains of antigen groups $08,09,020$, and 0101 grown under different conditions. Infect. Immun. 27:216-221.

10. Eisenstein, B. I., and D. C. Dodd. 1982. Pseudocatabolite repression of type I fimbriae of Escherichia coli. J. Bacteriol. 151:1560-1567.

11. Finley, B. B., and S. Falkow. 1989. Common themes in microbial pathogenicity. Microbiol. Rev. 53:210-230.

12. Göransson, M. K. Forsman, P. Nilsson, and B. E. Uhlin. 1989. Upstream activating sequences which are shared by two divergently transcribed operons mediate cAMP-CRP regulation of pilus-adhesin in E. coli. Mol. Microbiol. 3:1557-1565.

13. Göransson, M., K. Forsman, and B. E. Uhlin. 1988. Functional and structural homology among regulatory cistrons of piliadhesin determinants in Escherichia coli. Mol. Gen. Genet. 212:412-417.

14. Göransson, M., and B. E. Uhlin. 1984. Environmental temperature regulates transcription of a virulence pili operon in $E$. coli. 
EMBO J. 3:2885-2888

15. Grinstedt, J., P. M. Bennett, S. Higginson, and M. H. Richmond. 1978. Regional preference of insertion of Tn501 and Tn802 into RP1 and its derivatives. Mol. Gen. Genet. 166:313-320.

16. Hacker, J. 1990. Genetic determinants coding for fimbriae and adhesins of extraintestinal Escherichia coli. Curr. Top. Microbiol. Immunol. 151:1-27.

16a.Hacker, J., L. Bender, M. Ott, J.Wingender, B. Lund, R. Marre, and $W$. Goebel. 1990. Deletions of chromosomal regions coding for fimbriae and hemolysins occur in vitro and in vivo in various extraintestinal Escherichia coli isolates. Microb. Pathog. 8:213225.

17. Hacker, J., T. Jarchau, S. Knapp, R. Marre, G. Schmidt, T. Schmoll, and W. Goebel. 1986. Genetic and in vivo studies with $S$ fimbriae antigens and related virulence determinants of extraintestinal Escherichia coli strains, p. 125-133. In D. Lark (ed.), Protein-carbohydrate interactions in biological systems. Academic Press Inc., London.

18. Hacker, J., G. Schmidt, C. Hughes, S. Knapp, M. Marget, and W. Goebel. 1985. Cloning and characterization of genes involved in production of mannose-resistant, neuraminidase-susceptible (X) fimbriae from a uropathogenic O6:K15:H31 Escherichia coli strain. Infect. Immun. 47:434-440.

19. Hacker, J., T. Schmoll, M. Ott, R. Marre, H. Hof, T. Jarchau, S. Knapp, I. Then, and W. Goebel. 1989. Genetic structure and expression of virulence determinants from uropathogenic strains of Escherichia coli, p. 140-156. In E. Kass and C. Svanborg-Eden (ed.), Host-parasite interactions in urinary tract infections. University of Chicago Press, Chicago.

20. Isaacson, R. E. 1983. Regulation of expression of Escherichia coli pilus K99. Infect. Immun. 40:633-639.

21. Isberg, R. R., A. Swain, and S. Falkow. 1988. Analysis of expression and thermoregulation of the Yersinia pseudotuberculosis inv gene with hybrid proteins. Infect. Immun. 56: 2133-2138.

22. Källenius, G., R. Möllby, S. B. Svenson, J. Winberg, A. Lundblad, and S. Svensson. 1980. The $p^{k}$ antigen as receptor of pyelonephritic E. coli. FEMS Microbiol. Lett. 7:297-300.

23. Klemm, P., and G. Christiansen. 1987. Three fim genes required for the regulation of length and mediation of adhesion of Escherichia coli type I fimbriae. Mol. Gen. Genet. 208:439445.

24. Knapp, S., J. Hacker, T. Jarchau, and W. Goebel. 1986. Large unstable inserts in the chromosome affect virulence properties of uropathogenic Escherichia coli O6 strain 536. J. Bacteriol. 168:22-30.

25. Knapp, S., and J. J. Mekalanos. 1988. Two trans-acting regulatory genes (vir and mod) control antigenic modulation in Bordetella pertussis. J. Bacteriol. 170:5059-5066.

26. Korhonen, T. K., M. V. Valtonen, J. Parkkinen, V. VảisänenRhen, J. Finne, F. Ørskov, I. Ørskov, S. B. Svenson, and P. H. Mäkelä. 1985. Serotype, hemolysin production, and receptor recognition of Escherichia coli strains associated with neonatal sepsis and meningitis. Infect. Immun. 48:486-491.

27. Lederberg, E., and S. N. Cohen. 1974. Transformation of Salmonella typhimurium by plasmid deoxyribonucleic acid. J. Bacteriol. 119:1072-1074.

28. Magasanik, B., and F. C. Neidhardt. 1987. Regulation of carbon and nitrogen utilization, p. 1318-1325. In C. Neidhardt (ed.), Escherichia coli and Salmonella typhimurium: cellular and molecular biology, vol. 2. American Society for Microbiology, Washington, D.C

29. Maniatis, T., E. F. Fritsch, and J. Sambrook. 1982. Molecular cloning: a laboratory manual. Cold Spring Harbor Laboratory, Cold Spring Harbor, N.Y.

30. Marre, R., J. Hacker, W. Henkel, and W. Goebel. 1986. Contribution of cloned virulence factors from uropathogenic Escherichia coli strains to nephropathogenicity in an experimental rat pyelonephritis model. Infect. Immun. 54:761-767.

31. Maurelli, A. T. 1989. Temperature regulation of virulence genes in pathogenic bacteria: a general strategy for human pathogens? Microb. Pathogen. 7:1-10.

32. Miller, J. 1972. Experiments in molecular genetics. Cold Spring
Harbor Laboratory, Cold Spring Harbor, N.Y.

33. Miller, J. F., J. J. Mekalanos, and S. Falkow. 1989. Coordinate regulation and sensory transduction in the control of bacteria virulence. Science 243:916-922.

34. Miller, V. L., and J. J. Mekalanos. 1988. A novel suicide vector and its use in construction of insertion mutations: osmoregulation of outer membrane proteins and virulence determinants in Vibrio cholerae requires toxR. J. Bacteriol. 170:25752583 .

35. Moch, T., H. Hoschützky, J. Hacker, K. D. Krönke, and K. Jann. 1987. Isolation and characterization of the $\alpha$-sialyl- $\beta-2,3$ galactosyl-specific adhesin from fimbriated Escherichia coli. Proc. Natl. Acad. Sci. USA 84:3462-3466.

36. Olsen, A., A. Jonsson, and S. Normark. 1989. Fibronectin binding mediated by a novel class of surface organelles on Escherichia coli. Nature (London) 338:652-655.

37. Ørskov, I., and F. Ørskov. 1985. Escherichia coli in extraintestinal infections. J. Hyg. Cam. 95:551-575.

38. Ott, M., H. Hoschützky, K. Jann, I. van Die, and .I. Hacker. 1988. Gene clusters for S fimbrial adhesin (sfa) and F1C fimbriae $(f o c)$ of Escherichia coli: comparative aspects of structure and function. J. Bacteriol. 170:3983-3990.

39. Ott, M., T. Schmoll, W. Goebel, I. van Die, and J. Hacker. 1987 Comparison of the genetic determinant coding for the S-fimbria adhesin (sfa) of Escherichia coli to other chromosomally en coded fimbrial determinants. Infect. Immun. 55:1940-1943.

40. Parkkinen, J., T. K. Korhonen, A. Pere, J. Hacker, and S. Soinila. 1988. Binding sites in the rat brain for Escherichia col $\mathrm{S}$ fimbriae associated with neonatal meningitis. J. Clin. Invest. 81:860-865.

41. Parkkinen, J., B. N. Rogers, T. Korhonen, W. Dahr, and J. Finne. 1986. Identification of the O-linked sialyl oligosaccharides of glycophorin as the erythrocyte receptors for S-fimbriated Escherichia coli. Infect. Immun. 54:37-42.

42. Rigby, P. W. J., J. M. Dieckmann, C. Rhodes, and P. Berg. 1977 Labeling deoxyribonucleic acid to high specific activity in vitro by nick translation with DNA polymerase I. J. Mol. Biol. 113:37-251.

43. Roosendaal, B., P. M. P. van Bergen en Henegouwen, and F. K. de Graaf, 1986. Subcellular localization of K99 fimbrial subunits and effect of temperature on subunit synthesis and assembly. $J$. Bacteriol. 165:1029-1032.

44. Saukkonen, K. M. J., B. Novicki, and M. Leinonen. 1988. Role of type I and S fimbriae in the pathogenesis of Escherichia coli 018:K1 bacteremia and meningitis in the infant rat. Infect. Immun. 56:892-897.

45. Schmoll, T., J. Hacker, and W. Goebel. 1987. Nucleotide sequence of the $s f a A$ gene coding for the $\mathrm{S}$ fimbrial protein subunit of Escherichia coli. FEMS Microbiol. Lett. 41:229 235.

46. Schmoll, T., H. Hoschützky, J. Morschhäuser, F. Lottspeich, K. Jann, and J. Hacker. 1989. Analysis of genes coding for the sialic acid-binding adhesin and two other minor fimbrial subunits of the S-fimbrial adhesin determinant of Escherichia coli. Mol. Microbiol. 3:1735-1744.

47. Southern, E. M. 1975. Detection of specific sequences among DNA fragments separated by gel electrophoresis. J. Mol. Biol. 98:503-517.

48. Stan-Lotter, H., and K. E. Sanderson. 1981. Interactions of cations with membrane fractions of smooth and rough strains of Salmonella typhimurium and other gram-negative bacteria. J. Bacteriol. 146:542-551.

49. Stock, J. B., A. M. Stock, and M. Mottonen. 1990. Signal transduction in bacteria. Nature (London) 344:395-400.

50. Taylor, R. K. C Manoil, and J. J. Mekalanos, 1989. Broadhost-range vectors for delivery of TnphoA: use in genetic analysis of secreted virulence determinants of Vibrio cholerae. J. Bacteriol. 171:1870-1878.

51. van Die I., B. van Geffen, W. Hoekstra, and H. Bergmans. 1984. Type 1C fimbriae of a uropathogenic Escherichia coli strain: cloning and characterization of the genes involved in the expression of the $1 C$ antigen and nucleotide sequence of the subunit gene. Gene 34:187-196 
52. Van Verseveld, H. W., P. Bakker, T. van der Woude, C. Terleth, and F. K. de Graaf. 1985. Production of fimbrial adhesins K99 and F4l by enterotoxigenic Escherichia coli as a function of growth-rate domain. Infect. Immun. 49:159-163.

53. Virkola, R., B. Westerlund, H. Holthöfer, J. Parkkinen, M. Kekomäki, and T. K. Korhonen. 1988. Binding characteristics of
Escherichia coli adhesins in human urinary bladder. Infect. Immun. 56:2615-2622.

54. Williams, P. H., and G. Hinson. 1987. Temperature-dependen transcriptional regulation of expression of fimbriae in an Escherichia coli strain isolated from a child with severe enteritis. Infect. Immun. 55:1734-1736. 